\title{
Ultrasound Vs Tens in Painful Shoulder Syondrome
}

\author{
Ermira Ziçishti ${ }^{1}$, Artur Zoto ${ }^{2}$, Romena Suvaria ${ }^{3}$ \\ ${ }^{1,2,3}$ University Hospital Centre "Mother Theresa” Tirana Albania, Rruga e Dibres, nr 372, Tirana, Albania
}

\begin{abstract}
Painful shoulder is a very common problem treated by physiotherapy. Several approaches are described for the treatment and the rehabilitation of this problem.30 patients referred to our department of physiotherapy, University hospital center "Mother Theresa" with this problem are divided casually in 2 groups. The first group was treated with ultrasound and the other with TENS(both groups are also treated with local thermotherapy for $15 \mathrm{~min}$ ). The ultrasound and TENS are very effected at the treatment of this problem, especially for the patients that can't get other treatments because of their side effects. 1
\end{abstract}

Keywords: Painful shoulder, ultrasound, tens, vas, physiotherapy

\section{Introduction}

The general causes of painful shoulder are supraspinatus tendinitis, scapula-humeral periartritis and subdeltoid bursitis. ${ }_{5,9}$ Tendinitis and bursitis occur as consequences of repeated low grade irritation, strenuous activities, microtrauma that lead to inflammation that is associated with pain and limited ROM.Physiotherapy referred to many authors is very helpful in the treatment of this problem.Rule of thumb in a painful shoulder is to relief pain and to restore mobility.2,3,7

\section{Materials and Methods}

In the treatment of this problem in physiotherapy are used many modalities. The aim of our study is to compare the effectivity of ultrasound, TENSand exercises in the treatment of this pathology ${ }_{4}, 1030$ patients referred to our Department of Physiotherapy, University Hospital Centre "Mother Theresa",by rheumatologist or orthopedics doctor and diagnosed with supraspinatus tendinitis, scapulohumeral periartritis and subdeltoid bursitis are accepted in our study. The diagnose is confirmed with X-Ray too. The patients haven't take any NSAID or any other treatment during our study.

\section{Procedures}

Occasionally patients are divided in two groups. 15 are treated with ultrasound in scapula-humeral joint per $15 \mathrm{~min}$, starting with $0.5 \mathrm{w} / \mathrm{cm}^{2}$, increasing $0.1 \mathrm{w} / \mathrm{cm}^{2}$ each treatment to arrive $1 \mathrm{w} / \mathrm{cm}^{2}$ at the end of treatment. The second group is treated with TENS by 4 electrodes ( 2 in the anterior part and 2 in the posterior part of the joint).Patients are treated for 13 days in total( 5 days/per week). Our patients are also treated with infrared lamp for 15 min before ultrasound and TENS and Codman exercises after the electrotherapy. Before and after the treatment flexion and abduction are measured by standard goniometer.The pain is measured graphically with a visual scale.8

\section{Analysis}

To compare the two groups statistically is used the student test(Table and graphics).Wilcoxon test is used to compare pain and ROM before and after treatment for each group of patients. To compare the results for each treatment $U$ test is used.Probability's values $<5 \%$ are taken as significant values. The most important clinical and demographic datas are presented in the tables. The number of male patients is not equal in both groups, but this is not statistically significant, although the age of patients in the group treated with TENS is older than it in the other group.The improvement in the pain scale $(p=0.0001)$ and flexion $(p=0.007)$ are statistically significant for both groups The improvement in abduction, ultrasound $(p=0.03)$ and TENS $(\mathrm{p}=0.001)$ can't arrive $\alpha$ level.It was not arrived any significant difference in pain level and ROM between two groups taken in our study (pain $\mathrm{p}=0.94$, flexion $=0.98$, abduction $=0.50) .6$

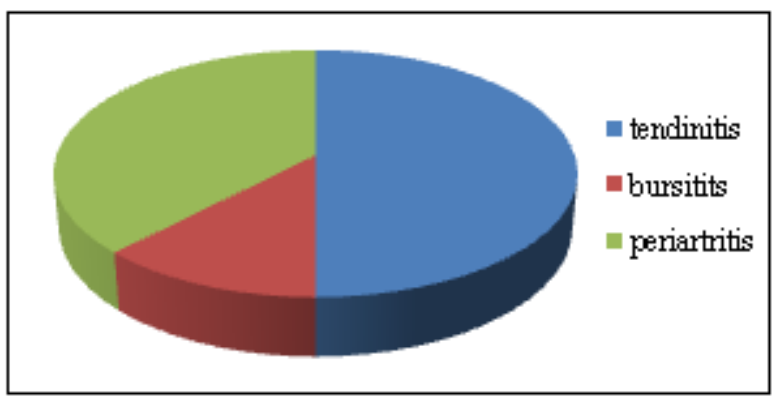

Figure 1:Pathologies treated with US and TENS

Table 1:Pathologies treated with US and TENS

\begin{tabular}{|c|c|c|c|c|c|c|}
\hline & Tendinitis & $\%$ & Bursitis & $\%$ & Periartritis & $\%$ \\
\hline US & 8 & 26.6 & 1 & 3.3 & 6 & 20 \\
\hline TENS & 6 & 20 & 3 & 10 & 6 & 20 \\
\hline
\end{tabular}
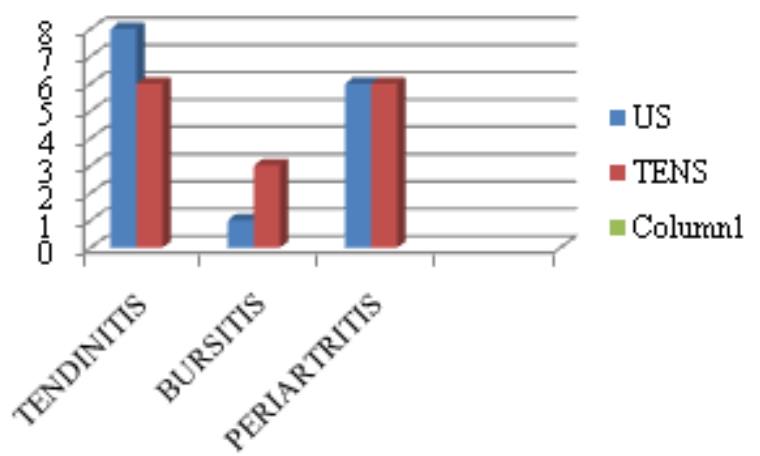

Figure 2: Pathologies treated with US and TENS 


\section{International Journal of Science and Research (IJSR) \\ ISSN (Online): 2319-7064}

Index Copernicus Value (2013): 6.14 | Impact Factor (2014): 5.611

Table 2: Abduction and flexion before and after treatment

\begin{tabular}{|c|c|c|c|}
\hline & Before treatment & After treatment & P value \\
\hline Abduction US & $136 \pm 54$ & $160 \pm 68$ & 0.03 \\
\hline Abduction TENS & $121 \pm 57$ & $150 \pm 67$ & 0.01 \\
\hline Flexion US & $137 \pm 57$ & $161 \pm 74$ & 0.007 \\
\hline Flexion TENS & $118 \pm 48$ & $145 \pm 64$ & 0.007 \\
\hline
\end{tabular}

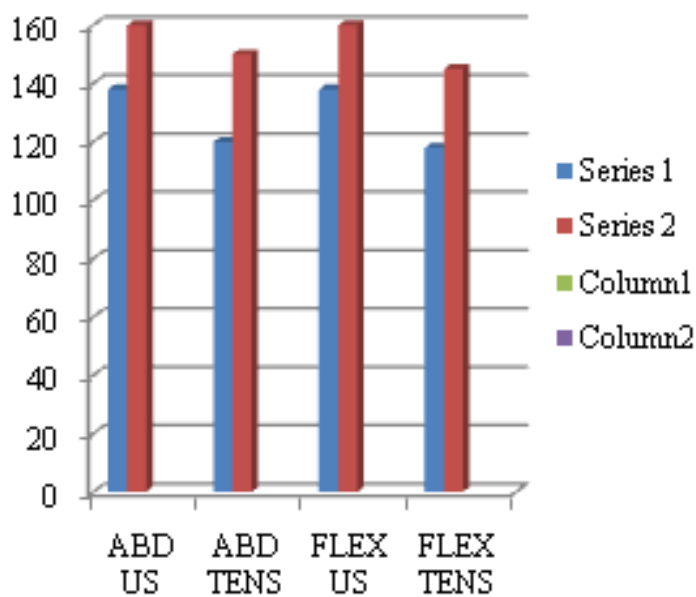

Figure 3: Abduction and flexion before and after treatment

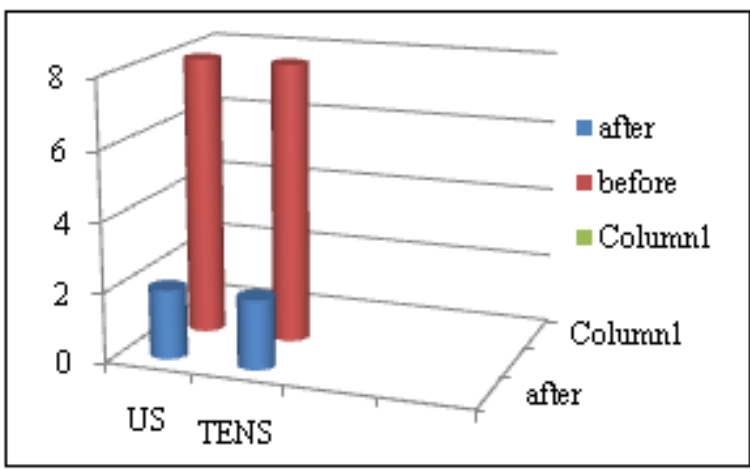

Figure 4: Pain scale before and after treatment

\section{Discussions}

The study evaluated and compared the effectivity of two therapeutic modalities in the treatment of painful shoulder syndrome. The pain and the loss of mobility are the main complains in this problem. Thedatas that we analyzed suggest that the use of ultrasound and TENS are equally effective in the treatment of the painful shoulder syndrome. Statistically the improvement of pain and ROM in flexion and abduction are significant in both treatments.

\section{Conclusion}

As we mentioned before, both groups are treated with 15 min local thermotherapy and exercises during all the sessions. In general in physiotherapy the problems are treated with different therapies. In the future is important to have more studies referred to many problems that we treat daily in our department. The ultrasound and TENS therapy are very effective in the treatment of painful shoulder and are effective alternatives for the category of patients that can't use NSAID or steroid injections because of their side effects

\section{References}

[1] Ann Thompson, Alison Skinner, Joan Piercy Tidy's Physiotherapy .US and Interferential Therapy Twelfth Edition, pp.460,461, 1992

[2] Physiotherapy volume.83 , Shoulder treatment pp.12$14,1997$.

[3] Shehab D, Adham N. [Comparative effectiveness of ultrasound and transcutaneous electrical stimulation in treatment of periarticular shoulderpain]. Physiotherapy; Canada 200052(3):208-210, 214.

[4] 4-Krusen's Handbook of Physical Medicine and Rehabilitation p.692,693 325,327, 1990

[5] 5- Bang M, Deyle G. [Comparison of supervised exercise with and without manual physical therapy for patients with shoulder impingement syndrome]. Journal of Orthopedic\& Sports Physical Therapy 2000;30(3):126-137.

[6] RiegelmanR(1979). The importance of significance and the significance of importance pp.66,119-129

[7] Ginn KA, Herbert RD, Khouw W, Lee R. [A randomized, controlled clinical trial of a treatment for shoulder pain]. Physical Therapy 1997;77(8):802-811.

[8] Huskisson, E.C.Jons J and Scott.Application of visual analoge scales to the measurements of functional capacity. Rheumatism and rehabilitation pp.15, 155-187

[9] Comite Editorial , Acta Medica Costarricense Painful shoulder syndrome. G.Portilla, SV.Narnjo yr.2011

[10] Physical therapy American Journal yr.1976Execessive scapular motion in individuals recovery from painful and stiff shoulder p.229-230

\section{Authors Profile}

Dr. Ermira Zicishti, Head of Department of Physiotherapy, University Hospital Centre, "Mother Teresa", Tirana Albania

Dr. Artur Zoto, Department of Rheumatology, University Hospital Centre, "Mother Teresa", Tirana Albania RomenaSuvarija, Department of Physiotherapy, University Hospital Centre, "Mother Teresa", Tirana Albania 